\title{
Q Going above and beneath the call of duty: the luck egalitarian claims of healthcare heroes, and the accomodation of professionally-motivated treatment refusal
}

\section{HEALTHCARE HEROES AND LUCK EGALITARIAN CLAIMS TO MEDICAL TREATMENT}

In 2014, American doctor Ian Crozier chose to travel to Sierra Leone to help fight the West African Ebola epidemic. He contracted Ebola himself and was evacuated to the US, where he received hospital treatment for 40 days.

Crozier knowingly chose to expose himself to a risk of contracting Ebola, and thus appears to be at least somewhat morally responsible for his infection. Did this responsibility weaken his justicebased claim to publicly funded treatment? On one influential view-luck egalitarianism—the answer is 'yes'. Or so Albertsen and Thaysen suggest in this issue. ${ }^{1}$

According to luck egalitarianism, justice requires the elimination of inequalities between people, but only when the relative harm borne by those on the wrong end of the inequality is a matter of luck. Albertsen and Thaysen understand luck egalitarianism to entail that, when one is responsible for befalling a harm, one has no claim in justice to the mitigation of that harm. On this view, they suggest, Crozier's claim to treatment would be similar to that of a reckless Alpine skier who is injured in a skiing accident, and would be weaker than that of those with a normal claim to treatment-those who bear no responsibility for their illness. Both of these implications seem implausible, however. Intuitively, Crozier's claim to treatment is no weaker than those with normal claims, and certainly stronger than the reckless skier's.

Can luck egalitarianism be 'adjusted or interpreted' so as to avoid these implausible implications? The authors suggest that it can. Their innovation is to distinguish heroic doctors like Crozier from reckless skiers by invoking a distinction between being responsible for creating harm and for incurring harm. Their thought is that one creates harm when one brings harm on oneself without also preventing at least as much harm to others. Thus, the harm that one befalls is, at least in part, a new harm that one has brought into the world. By contrast, one merely incurs harm when one brings harm on oneself but also prevents at least as much harm to others. In these cases, the harm one befalls was in effect simply shifted onto oneself from others.

Heroic doctors like Crozier are responsible for incurring harm, but not for creating it, for their actions can be expected to prevent more harm to others. On the other hand, the reckless skier is responsible for creating harm. This, the authors think, makes the moral difference. Their revised (or reinterpreted) version of luck egalitarianism holds that those responsible for creating harm have a weakened claim to treatment, but those merely responsible for incurring it do not.

The authors' proposal seems to me be heading in the right direction, but not quite on target. A problem with it can be brought out by considering the following, hypothetical case: A child is drowning. Her mother jumps in to try to save her, knowing that the chances of a successful rescue are tiny, and the risk to herself is significant. She believes that good parents must do all they can in such scenarios, and besides, she had once promised her child that she would never give up on him in such a case. Unsurprisingly, the rescue attempt fails, and the mother ends up with some injuries herself. Does the mother have a lesser claim to treatment, comparable to that of the reckless skier? Intuitively not. But the authors' variant of luck egalitarianism cannot accommodate this intuition, for this mother is surely responsible for creating, rather than merely incurring, the harm that she befalls.

Can we further modify luck egalitarianism to get the right result in this case? I think we can. We simply need to hold that what matters is not merely being responsible for incurring harm, but being culpable or blameworthy for incurring it. (This view has been defended by Eyal, ${ }^{2}$ and is criticised elsewhere by Thaysen and Albertsen. ${ }^{3}$

To be responsible for a choice is to be liable to moral appraisal in the light of that choice. To be culpable for it is to be liable to (a certain kind of) negative moral appraisal in the light of that choice. One can be responsible for a choice without being blameworthy, for example, because the choice was a morally good one (so that one is instead praiseworthy) or because, though one performed a morally bad action, one had an excuse for performing it.

The mother of the drowning child is at least somewhat responsible for incurring harm, but is not blameworthy for incurring it, and this explains, I believe, why her claim to medical treatment is not weakened. By contrast the reckless skier arguably is blameworthy for incurring harm, and this may explain why his claim to public funded treatment is weakened.

This blameworthiness-based version of luck egalitarianism also helps to deal with another sort of case. Suppose that Dr Hozier, like the real Dr Crozier, went to West Africa to help treat patients during the Ebola epidemic, and ended up being infected herself. But suppose that, unlike Crozier, Hozier was motivated purely by the prospect of financial and reputational rewards; she in fact cared nothing for the well-being of those afflicted by Ebola, and indeed thought-incorrectly as it turns out-that her work would do more harm than good to others. Hozier may well have foreseeably prevented more harm than she befalls, thus being responsible only for incurring harm in Albertsen and Thaysen's terms. Yet it is not so clear that her claim to medical treatment is preserved. Her claim may be weakened, I suggest, because she is blameworthy for incurring that harm.

\section{PROFESSIONAL NORMS AND MORALLY MOTIVATED TREATMENT REFUSAL}

Albertsen and Thaysen's discussion concerns cases in which healthcare workers go beyond the call of duty. Elsewhere in the issue, Magelssen ${ }^{4}$ discusses a case in which a healthcare worker declines to carry out what would generally be regarded as part of his duty.

The case is that of a Norwegian psychiatrist who moves to a town where he is expected to prescribe buprenorphine as part of opioid replacement therapy. 
After discovering that one of his patients has been selling his buprenorphine to a vulnerable individual, the psychiatrist comes to the view that he ought no longer to participate in the opioid replacement therapy scheme, and seeks to opt out of it.

Magelssen uses this case to illustrate what he takes to be a deficit in the ethical debate on whether and when healthcare workers should be allowed to opt out of providing treatments which they take to be immoral. This literature has typically focused on cases in which a doctor refuses to provide a controversial but officially endorsed medical intervention, such as abortion, on the basis of a principled and personal moral objection (often referred to as a 'conscientious objection'). Magelssen argues that the Norwegian psychiatrist's moral objection was more situational than principled, and more professional than personal. Yet the objection was not, in his view, thereby clearly less grave, and it is not clear why it should have any weaker claim to being accommodated than principled and personal objections.

Though Magelssen does not himself pursue this issue, his discussion raises the question of how we should delineate specifically professional moral objections. I take it that a healthcare worker has a professional moral objection when she believes some action would be morally impermissible in virtue of violating what she takes to be a professional moral norm.

Which moral norms are the professional ones? I can see three somewhat plausible ways of answering these questions.

First, we could delineate professional norms on the basis of their scope of application. Professional moral norms are moral norms that apply to all healthcare professionals (of a given type) qua their being healthcare professionals (of that type). These could be contrasted with other moral norms that apply to everyone, or to some subset of individuals not picked out by their professional role (for example, people who hold certain religious views).

Second, we could mark out professional moral norms on the basis of their source. Professional moral norms derive ultimately from professional rules and conventions-what Miola has referred to as the 'corporate conscience' of the medical profession ${ }^{5}$ - perhaps combined with some objective moral requirement to respect those rules and conventions, at least where they are reasonable. Thus, for example, professional convention requires that doctors not withhold treatments on the basis that they dislike the patients requesting them. If doctors have at least a defeasible moral obligation to comply with reasonable professional conventions, and if this convention is indeed reasonable, which it surely is, then this conventional requirement will give rise to a moral requirement: a professional moral norm prohibiting the refusal of treatments on the basis of personal dislike. Professional moral norms, on this account, can be contrasted with norms that ultimately derive solely from, say, objective morality, general societal rules and conventions, or one's personal commitments.

Third, we could mark out professional moral norms on the basis of their scope of endorsement. Moral norms count as professional if they would be endorsed by almost all members of the profession, or perhaps if they are codified in (if not derived from) the rules and conventions of the profession. These can be contrasted with moral norms that are less widely endorsed within the profession, or not codified in its rules and conventions.

It seems to me that none of these ways of delineating professional moral norms, and thus professional moral objections, is hospitable to the view that professional objections necessarily have a weaker claim to accommodation than other moral objections. On all three accounts, it is quite possible for professional moral objections to be as strongly held, robust, sincere and central to one's identity as other moral objections.

Indeed, if professional moral norms are characterised by their source-their deriving from professional rules or conventions-one might think that professional objections will generally have a stronger claim to accommodation than other moral objections. This is because those with such objections may find it more difficult to excuse their conduct if they override their objections and provide the treatment to which they object. To see why, consider the classic case of morally motivated treatment refusal: refusal to perform abortions. Those who offer such refusals are standardly portrayed as offering a non-professional moral objection along the following lines: 'Look, I know that the conventions of medicine allow abortions, but I'm not personally convinced that it is morally permissible for me to perform them, so I decline to do so.' Were a doctor with such an objection to go against her conscience and perform an abortion, she might seek to excuse herself in the following way: 'I don't think that performing abortions is morally permissible; I think I act wrongly in performing them. But I'm not blameworthy for performing them, because in doing so, I'm simply deferring to the conventions of my profession. If anyone is to blame, it's those who uphold those conventions.' It's doubtful whether this sort of 'just following orders' reasoning can in fact excuse a morally impermissible action, but it seems likely that it does offer some comfort to those who go along with professional conventions, yet feel moral distress about doing so.

Notice, however, that this sort of reasoning is not available to the healthcare worker whose objection to providing a treatment is professional, in the sense that the objector takes the norm at stake to derive from professional rules and conventions. If this objector goes along with the treatment that she believes to be impermissible, she cannot coherently seek to shift responsibility to the rules and conventions, or those who uphold them, for she believes that those rules and conventions in fact militate against the treatment. This objector may thus find it more difficult to live with her moral distress, and that may give her a stronger claim to accommodation.

Acknowledgements I would like to thank Nir Eyal, Alberto Giubilini and Katrien Devolder for their comments on an earlier draft of this article.

Competing interests None declared.

Provenance and peer review Commissioned; internally peer reviewed.

(c) Article author(s) (or their employer(s) unless otherwise stated in the text of the article) 2017. All rights reserved. No commercial use is permitted unless otherwise expressly granted.

\section{REFERENCES}

1 Albertsen A, Thaysen JD. Distributive justice and the harm to medical professionals fighting epidemics. J Med Ethics 2017;43:861-4.

2 Eyal N. Egalitarian justice and innocent choice. J Ethics Soc Phil 2006;2:1-18.

3 Thaysen JD, Albertsen A. When bad things happen to good people: luck egalitarianism and costly rescues. J Politics Philos Econ 2017;16:93-112.

4 Magelssen M. Professional and conscience-based refusals: the case of the psychiatrist's harmful prescription. J Med Ethics 2017;43:841-4.

5 Miola J. Making decisions about decision-making: conscience, regulation, and the law. Med Law Rev 2015;23:263-82 
Correction: Going above and beneath the call of duty: the luck egalitarian claims of healthcare heroes, and the accomodation of professionally-motivated treatment refusal

Douglas T. Going above and beneath the call of duty: the luck egalitarian claims of healthcare heroes, and the accomodation of professionally-motivated treatment refusal. J Med Ethics 2017;43:801-802. doi:10.1136/medethics-2017-104656.

There was a typo in the title of this paper, 'accomodation' should be 'accommodation'.

(c) Article author(s) (or their employer(s) unless otherwise stated in the text of the article) 2018. All rights reserved. No commercial use is permitted unless otherwise expressly granted.

J Med Ethics 2018;44:142. doi:10.1136/medethics-2017-104656corr1

A) Check for updates 